\title{
EXPERIMENTAL PIGMENTARY DEGENERATION OF THE RETINA BY SODIUM IODATE
}

BY

\author{
ARNOLD SORSBY
}

LONDON

Septojod, ${ }^{*}$ which appears to have been introduced in 1920 , has been used widely in German-speaking countries for septic conditions on the assumption that nascent iodine is liberated by this preparation in the presence of septic material. It has been especially popular in the treatment of puerperal sepsis.

In 1926, Schimmel and Riehm reported two cases of blindness following the intravenous injection of 150 c.c. septojod in patients with puerperal septicaemia. The blindness came on within twenty-four hours, whilst the fundi showed no abnormality; within the course of a few days oedema of the macular region set in to be followed by diffuse pigmentary changes all over the fundus, reminiscent of retinitis pigmentosa. In the same year, Scheerer reported a similar case, describing the fundus changes fully and regarding the condition as an acute tapeto-retinal degeneration. Further cases have been reported by Riehm (1927), Roggenkämper (1927), von Bunau (1929), Sallmann (1933), and Ohm (1934). Roggenkämper's patient had undergone an operation for varicose veins and the track left by the excised veins had been washed out with 380 c.c. of septojod; Ohm's patient had 150 c.c. injected in a ligated saphenous vein ; Sallmann's patient, who suffered from tuberculous peritonitis, had undergone appendicectomy and the abdominal cavity had been flushed with 300 c.c. Pregl's solution, whilst the remaining cases-those of Riehm and von Bunau-were like the first three, cases of puerperal septicaemia. Ophthalmoscopically the patients all showed very similar appearances; a good coloured drawing is given by Riehm (1929). Variable field defects are reported and end results, varying from little recovery to practically complete recovery of vision, are noted. As to aetiology the later cases negative the suggestion made by Scheerer on the early cases, viz., that the retina is affected by septojod only in cases of puerperal sepsis with its preceding loss of blood, and possible damage to the liver from chloroform.

* A German iodine preparation, the exact composition of which is a trade secret, is said to contain sodium hypoidide and sodium hypoiodate. According to Fernau, Pregl's solution (the basis of septojod which is said to be this solution ten times concentrated) contains iodide, hypoiodate, bicarbonate and chloride all as sodium salts and also free iodine. Gehr's Codex 1937 gives it as consisting of iodine, hypoiodide, iodate and a small quantity of free iodine. 
The toxic component of septojod.-In reporting the first two cases (Schimmel and Riehm) Riehm gave experimental evidence to implicate septojod; in 18 rabbits $2.5-5.0$ c.c. septojod per kilo injected intravenously produced an ophthalmoscopic picture similar to that they had observed clinically. In albino rabbits no tangible ophthalmoscopic changes were found. These findings are constant and have been confirmed by all the subsequent observers who have dealt with the experimental aspect of the subject. Sallmann investigated experimentally the toxic action of iodine, sodium iodide and sodium hypoiodate and concluded that it was the hypoiodate component of septojod which was responsible for the retinal degeneration, for ophthalmoscopically and histologically it gave regularly the same appearances as are given by septojod degeneration. Sodium hypochloride and sodium hypobromide could not be injected in corresponding quantities as they are highly irritating, and in the concentrations used gave no ophthalmoscopic changes, though the neuro-epithelium showed histological damage. Vito (1935), impressed by the fact that hypoiodate is an unstable compound, becoming readily converted into iodate on exposure to air, light, changes in temperature, and in acid media, attempted to obtain retinal degeneration by the action of sodium iodate alone. This he achieved in rabbits by injecting [?intravenously] $\frac{1}{2}-1$ c.c. per kilo of 4.52 per cent. sodium iodate daily for 10-15 days. Fundus changes appeared early. Kalt (1937) confirmed these observations, but used the subcutaneous route, injecting 1 c.c. of 4 per cent. solution per kilo under the abdominal skin, and repeating it every second day, giving twenty to thirty injections.

Lesions in tissues other than the retina.-Riehm, Sallmann and Vito, all reported that no damage to other tissues could be detected in pigmentary retinal degeneration produced by septojod or by sodium hypoiodate and sodium iodate. Umadzume (1929) appears to have noted lesions in the liver, as also-in contrast to other observers-rather extensive changes in the eye involving the ciliary body and lens; it is, therefore, possible that he used exceptionally high doses. Areas of necrosis in the liver and much infiltration with Kupfer cells is also reported by Kalt, whilst Koyanagi and Kinukawa (1937) report drop-like hyaline degeneraof the cells of the kidney tubules, though it should be pointed out that they used rather massive doses $(30$ c.c. septojod intravenously repeated after nine hours in one rabbit; 10 c.c. repeated three times after intervals of 2-3 days in another; and 5-10 c.c. repeated after an interval of one day or longer.)

Ophthalmoscopic and histological appearances-The ophthalmoscopic appearances seen experimentally and the histological findings as reported by the different observers-Riehm, Scheerer, 
Umadzume, Sallmann, Vito, Homma and Kalt-constitute a clear-cut picture. Illustrations of the fundus appearances in rabbits are given by Riehm, Scheerer, Vito, Kalt and by Sorsby et alia (1937) and Sorsby (1940). (See also Figs. 1 and 2). The absence of pigmentary changes ophthalmoscopically in albino rabbits has been noted by Riehm and subsequent observers, but histological changes in the colourless pigment layer and the neuro-epithelium are stressed by Homma (1935).

The histological changes, as reported by different observers, constitute a clear picture. In the earliest stages the changes are confined to the pigment epithelium, which shows proliferation uniformly, with some heaping up here and there. At more advanced stages, active migration of the pigment cells, normal and altered, into the layers of the retina is seen, and the rods and cones become disorganized to the point of being unrecognisable as such. Some oedema of the ganglion cell layer may be present and occasionally some pigment cells may have migrated as far forwards, but essentially this layer remains unaffected. The choroid is not implicated at all. There is complete absence of any inflammatory or reparative reaction. There is some difference of opinion as to a subsidiary feature; Riehm described exudates between the retina and the pigment epithelium; these Scheerer regarded as artifacts; Homma more recently stressed massive albuminous exudate arising from the pigment epithelium and separating it from the retina, as an essential feature of the process.

\section{Personal Observations}

(1) Dosage for experimental pigmentary degeneration of the retina.-Previous observers, give the necessary dose for the rabbit as $5-10$ c.c. of septojod intravenously. Ten c.c. are generally well tolerated, but degeneration can be obtained in most cases by one injection of 6 c.c. Within a week the ophthalmoscopic changes are unmistakable; within a fortnight they are fully established.

As for sodium iodate, it is not necessary to give repeated subcutaneous injections. One intravenous injection of 5 c.c. of the 2 per cent. solution gives satisfactory results (Fig.3). The margin between the effective and lethal dose is narrow. For the fully grown rabbit, 2 kilos in weight, 4 c.c. may be ineffective, and 6 c.c. fatal. The solution of sodium iodate is best when freshly prepared. Old solutions undergo a change of colour, becoming yellowish.

(2 Lesions in the viscera.-A massive dose of sodium iodate, such as 8 c.c. of the 10 per cent. solution, is lethal within 20 minutes. Clinically air-hunger develops, the head is retracted and the animal dies during a fit of convulsions. Post-mortem extensive necrosis of the liver is present, histological detail being largely lost. With a dose effective for pigmentary degeneration 


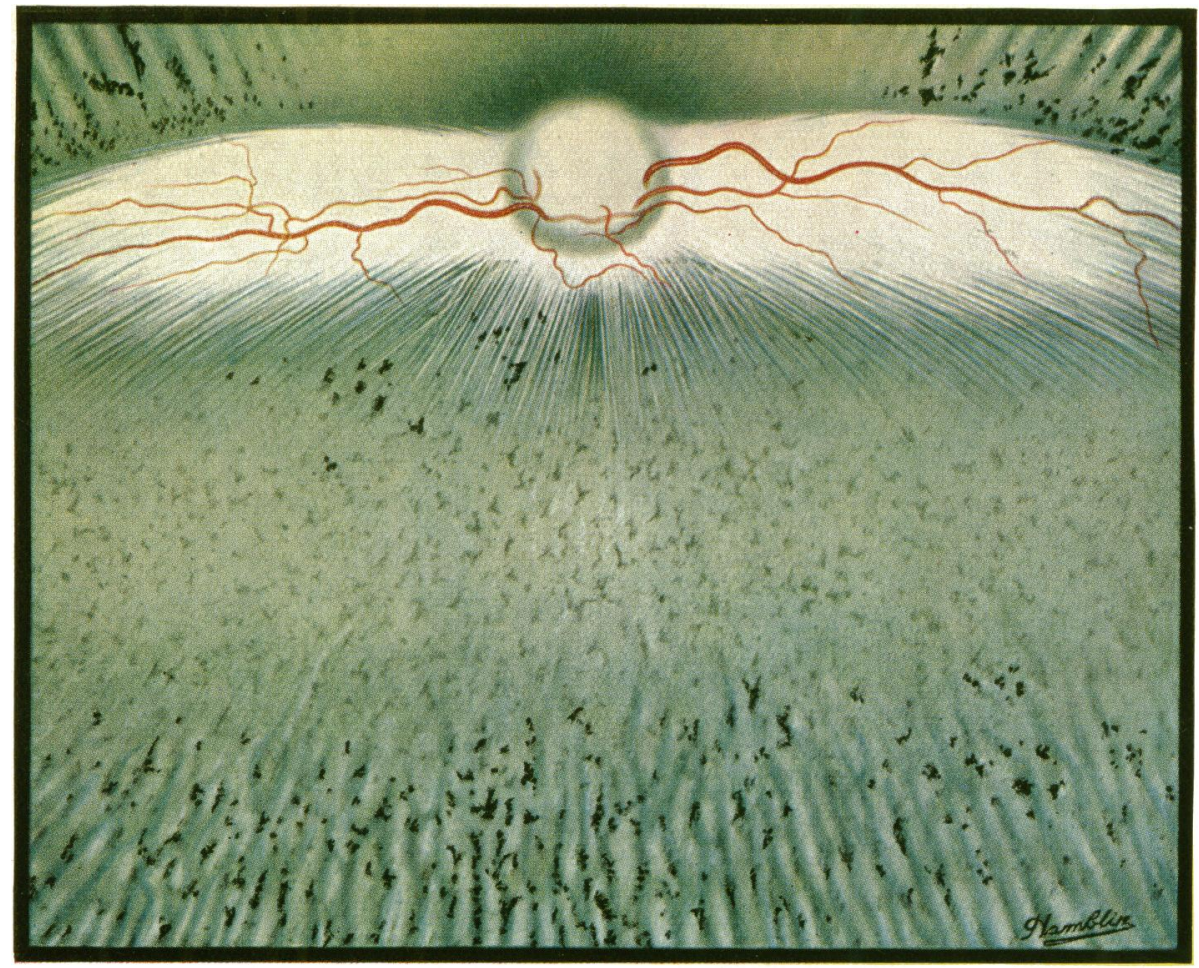

FIG. 1.

Rabbit's fundus showing pigmentary degeneration of the retina caused by intravenous in jection of septogod.

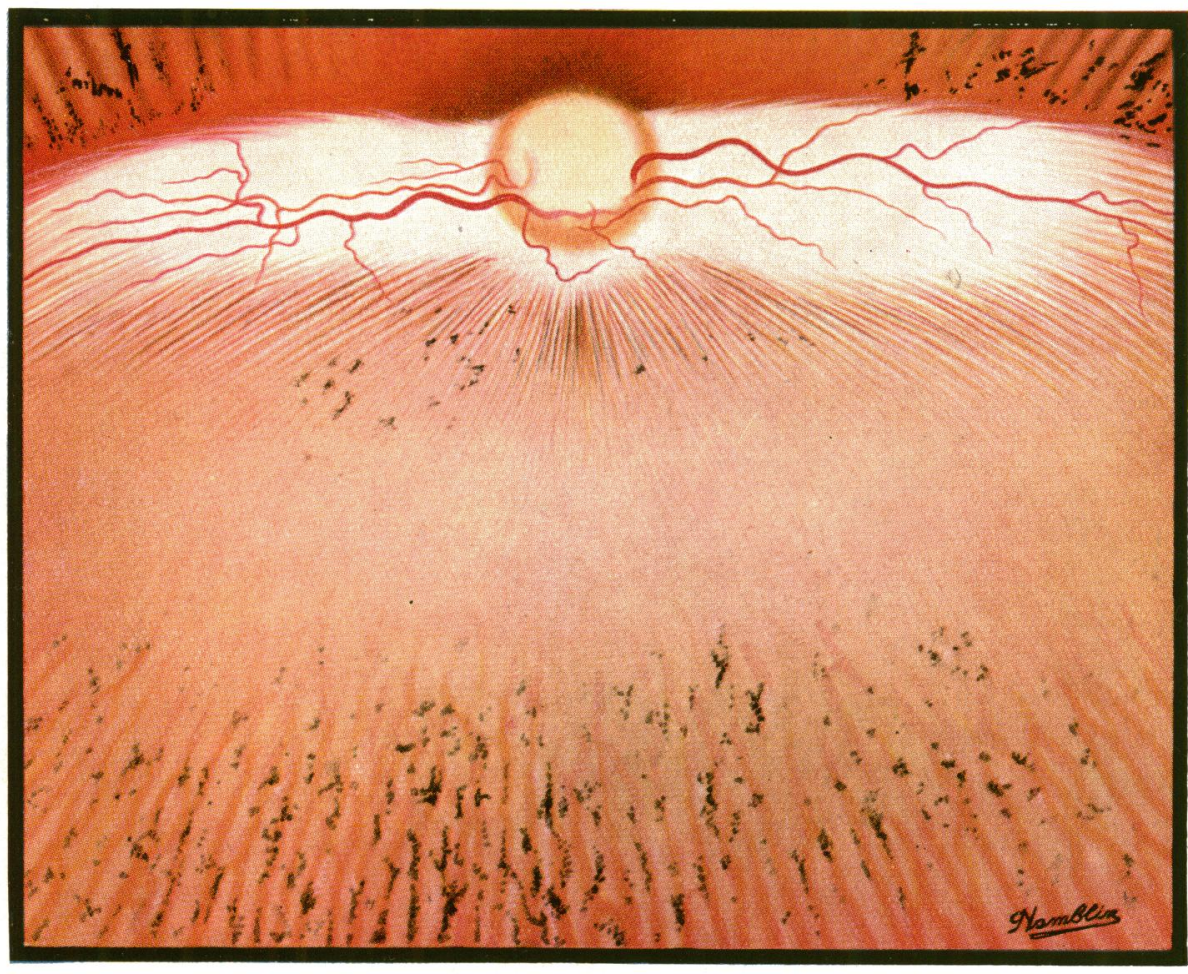

FIG. 2.

The same fundus as in Fig. 1 after intravenous in jection of light green S.F.

From Proceedings of the Royal Society of Medicine, 1937. 
of the retina, it is difficult to be convinced that the liver or kidney show any histological changes. This, however, does not exclude the possibility of functional damage of these organs. The changes reported by Umadzume, Kalt and by Koyanagi must be ascribed not to a dose effective for retinal degeneration but to toxic quantities.

In animals that have been treated with quantities of sodium iodate sufficient to induce retinal changes, and even in those that have two such effective doses (5 c.c. of the 2 per cent. solution), the liver on post-mortem examination failed to show any evidence of necrosis or of cellular infiltration. There was, however, well marked, cloudy swelling of the liver cells throughout the organ with loss of normal glycogen granules. No such changes were observed in control animals. These changes in the liver cells do not represent any permanent damage; indeed recovery was to be expected.

(3) The changes in albino rabbits.-The absence of ophthalmoscopically visible changes induced by septojod in albino rabbits, does not imply that the neuro-epithelium is not damaged. This was pointed out on histological evidence by Riehm and by Homma. Clinically this could be demonstrated by vital staining by the method described elsewhere (Sorsby, 1937, 1939, 1940.) The retina of the normal albino rabbit behaves like that of the pigmented animal in decolourising Kiton Fast Green injected intravenously. Albino rabbits treated with septojod or sodium iodate, whilst not showing any ophthalmoscopically visible changes, show staining of the fundi in the same way as treated pigmented animals-after a transient flush of colour in the fundus, no colour is seen, until the onset of gradually deepening coloration.

I am indebted to Dr. John O. Oliver for his kindly help with the study of histological preparations and for carrying out the experiments dealing with the effect of iodate on the liver. To Messrs. Butterworth \& Co. (Publishers), Ltd., I am indebted for the loan of the colour blocks taken from Modern Trends in Ophthalmology, published by them.

\section{Summary}

1. A review is given of the clinical cases in which the use of septojod led to transient or permanent loss of vision from pigmentary changes in the retina.

2. The experimental work leading to the incrimination of sodium iodate as the toxic agent is indicated.

3. The dosage for the experimental production of pigmentary degeneration of the retina in the rabbit is shown as 5 c.c. of the 2 per cent. solution injected intravenously. 
4. There is no evidence that with this dosage there is any permanent damage to other tissues, so that sodium iodate may be regarded as a selective poison to the retina.

5. By means of the method of vital staining with Kiton Fast Green it is shown that the retina is damaged by iodate in the albino rabbit though no pigmentary disturbances are seen ophthalmoscopically.

\section{REFERENCES}

v. Bunau.-Klin. Monatsbl. f. Augenheilk., Vol. LXXXIII, p. 345, 1929.

Hoмma.-Arch.f. Ophthal., Vol. CXXXIV, p. 305, 1935.

KaLt.-Bull. Soc. Ophthal., Paris, p. 304, 1937.

Koyanagi and KinUKaWA.-Arch. f. Ophthal., Vol. CXXXVII, p. 261, 1937.

Онм.-Zeitschr.f. Augenheilk., Vol. LXXXIII, p. 339, 1934.

RIEнм.-Klin. Monatsbl. f. Augenheilk., Vol. LXXVIII, p. 87, 1927 ; Arch. f. Ophthal., Vol. C-CI, p. 872, 1929.

Roggen KaMPER.-Klin. Monatsbl.f. Augenheilk., Vol. LXXIX, p. 827, 1927.

Sallmann.-Zeitschr. $f$. Augenheilk., Vol. LXXX, p 342, 1933.

SCHEERER.-Klin. Monatsbl.f. A ugenheilk., Vol LXXVI, p. 524, 1926 ; Ber. deut. ophthal. Gesellsch., Vol. XLVI, p. 315, 1926.

SCHIMMEL and RIEHM.-Münch. Med. Wochenschr., p. 590, 1926.

Sorsby, Elkeles, Goodhart and Morris.-Proc. Roy. Soc. Med., Vol. XXX, p. $1271,1937$.

Sorsby.-Brit. Jl. Ophthal., Vol. XXIII, p. 20, 1939 ; Trans. Ophthal. Soc. U.K., Vol. LIX, p. 727, 1939; Modern Trends in Ophthalmology, edited by F. Ridley and A. Sorsby, pp. 237-241, London, 1940.

UmADzUme.-Ref. Centralbl. $f$. Ophthal., Vol. XXII, p. 836, 1929.

Vito.-Boll. d'Ocul., Vol. XIV, p. 945, 1935.

\section{THE NATURE OF EXPERIMENTAL DEGENERATION OF THE RETINA}

BY

\section{ARNOLD SORSBY}

LONDON

In the preceding paper an account was given of pigmentary degeneration of the rabbit's retina induced by intravenous injection of 5 c.c. of 2 per cent. solution of sodium iodate. It was shown that the essential lesion was damage to the neuro-epithelium, the pigmentary changes being absent in albino rabbits, and that furthermore in doses effective for retinal damage, sodium iodate acted as a selective poison for the retina.

The selective action of sodium iodate on the retina, raised the question whether some specific retinal metabolic process was disturbed by this chemical. The possibility presented itself that the iodate-a powerful oxidising agent-destroyed or disturbed the 